\title{
VICISITUDES DEL REINO TAIFA DE DENIA EN LOS DOS TERCIOS ULTIMOS DEL SIGLO XIII
}

\author{
Dr. Juan Manuel del Estal \\ Universidad de Alicante
}

En la historia del SHARQ AL-ANDALUS de esta centuria aparecen algunos Reinos musulmanes, como los de MURCIA y VALENCIA, con entidad muy definida y sobresaliente, mientras que otros de menor duración e inferior solidez territorial, cual los de SEGORBE, ALMERIA y ALClRA-JATIVA y DENIA, fueron más fugaces y en consecuencia menos importantes y conocidos. De los primeros se conserva amplia información cronística y diplomática, tanto en fuentes árabes como cristianas (MOLINA LOPEZ, 1980; TORRES FONTES, 1980; GUICHARD, 1980; UBIETO, 1976 y 1979; ARIE, R., 1982), que están siendo objeto de intensa investigación histórica, mientras que de los restantes escasean más las fuentes de esta época y los estudios historiográficos sobre los mismos son casi inexistentes y muchos menos (HUICI MIRANDA, 1970; LLORENS, 1959; CHABAS, 1874; MOLINA LOPEZ, 1978 y 1979, 1981 y 1982; RUBIERA MATA M. J., La Taifa de Denia, Alicante, 1985). Por donde se dispone de muy pocos datos de estos Reinos últimos y muy particularmente del que nos ocupa en esta Comunicación, el REINO DE ALCIRA, JATIVA y DENIA, en los tres lustros finales de su existencia (1228-1243/44), de los que apenas se conoce documentación (BARCELO TORRES, 1981), a excepción de los escritores Denienses o Addâni, «que son tantos y están relacionados con Denia en los siglos XI al XIII, teólogos, juristas, poetas, filólogos, filósofos, astrónomos, musicólogos, etc., que queda aún muchísimo por investigar sobre el papel cultural de esta ciudad en Al-Andalus y, sobre todo, en Sharq Al-Andalus, que es el que representa lo más escogido de la cultura andalusí durante ese periodo, después de haberlo sido Andalucía del IX al XI y antes del esplendor granadino, al final de la época musulmana en la Península» (EPALZA, 1983). 
Por todo ello la documentación historiográfica es muy escasa y al presente muy poco conocida, razón por la que invitamos desde aquí a los arabistas todos que se ocupan de estos temas apuntados, a ahondar más en la búsqueda de fuentes de procedencia musulmana, al par que nosotros lo hacemos en las restantes cristianas, con el objetivo único y común de alcanzar mayor volumen de información documental sobre las postrimerias de estos Reinos taifas, en su esfuerzo admirable de supervivencia, frente al avance arrollador castellano-aragonés de la Reconquista peninsular.

Por cuanto a mi respecta en el caso presente voy a limitarme a ofrecer, a modo de Ensayo, las vicisitudes por que pasó este REINO en tres etapas sucesivas, la HUDITA (1229-1243), la CASTELLANA (1243-1244) y la ARAGONESA-VALENCIANA (1244-1304).

\section{REINO DE DENIA BAJO LA DINASTIA HUDITA (1229-1243)}

A la muerte del sultán Yusuf // (1224), la crisis infligida al Imperio Almohade en la batalla de las Navas (1212), se agudizó de tal suerte que puso en serio peligro su propia existencia. El movimiento independentista resurgió con nuevos brios, negando la obediencia al sucesor Abd alWāhid los viejos Reinos de Baeza y Valencia, en la persona de Abd Allāh y ABU ZAYD, respectivamente, al par que en Murcia lo hacía al-Adil; y en Sevilla su hermano, Abū-l-Ulà al-Mamūn, originando una política antialmohade tan radical que ocasionó su ruina.

Sobresalieron en esta empresa antialmohade particularmente los Reinos de Valencia y Murcia, cuyos caudillos respectivos ZAYYAN B. MARDANIS y un descendiente de los Banū Hud de Zaragoza, IBN HUD AL-MUTAWAKKIL, iniciaron en la misma fecha y gobernaron los mismos años sus correspondientes reinos, por un decenio revolucionario (12281238). Mientras el primero desarrolló una política prohafsi de acercamiento a Túnez, el segundo se autodeclaró proabbásisa, obediente a Bagdad.

Tras deponer ZAYYAN al sayyid de Valencia, Abū Zayd (1228), incorporó a su Reino Alcira, Játiva y DENIA, ensanchando así su frontera meridional. Pero por muy poco tiempo. En otoño del 1229 IBN HUD desencadenó una política de acercamiento a su causa antialmohade y unitaria de Al-Andalus bajo su cetro, con tal éxito que una tras otra se le sometieron espontáneamente las ciudades todas de Al-Andalus: Almeria, Granada, Jaén, Córdoba, Sevilla y Málaga, a excepción de Niebla, Algeciras y muy pocas más, acatándolo como lugarteniente y Emir del Califato abbásida. «Las ciudades de Levante (puntualiza MOLINA LOPEZ, 1980, 196, a quien seguimos en esta exposición) a excepción de Valencia (que siguió fiel a Zayyan, su rey) no tardarón en seguir el ejemplo de las anteriores. Los gobernadores de DENIA y ALCIRA, Abū Zakariyā y $A b \bar{u}$ 
Abd Alläh b. Abi Sultān, reconocieron a IBN HUD en sawwāl del año 626, comienzos de septiembre de 1229. Y el gobernador de JATIVA, Ahmad b. Isà $A b \bar{u}$ l-Husayn, lo hizo asimismo en aquel mes. La revolución de Ibn Hūd habia sido un éxito". En 1232 intentaría el rey de Murcia someter también a Zayyan de Valencia, pero en vano. Consiguió, empero, dominar casi todo Al-Andalus y extender las fronteras del Reino hudita desde Almería a Cádiz y desde Málaga a Alcira, protagonizando uno de los momentos más significativos de AL-ANDALUS en el siglo XIII.

Pero estrella tan propicia iba a empezar a apagarse muy pronto. $Y$ así el año 1233, el movimiento impulsado por Alfonso IX de León al avance de la Reconquista con la ocupación de Cáceres y Badajoz, encontró su mayor continuador en Fernando III, quien logró por entonces acercarse en marcha arrolladora a las propias puertas de Andújar, Córdoba y Jerez (GONZALEZ, Julio, 1951, 1980, 1983; GONZALEZ JIMENEZ, 1975; ARJONA CASTRO, 1980), amenazando con alcanzar el avance castellano el medio y bajo Guadalquivir.

El propio Al-Andalus comenzó a resquebrajarse en su obediencia unitaria a Ibn Hūd, surgiendo una vez más los brotes de independencia taifal. Iniciará este movimiento un caudillo rebelde, Muhammad b. NASR B. AL-AHMAR, en Arjona, arrastrando tras de sí a las ciudades de Jaén, Porcuna y CORDOBA, convirtiéndose muy pronto (mayo 1237) en un serio rival de Ibn Hud y en el poderoso monarca de la nueva dinastía nazari en el REINO DE GRANADA, (ARIÉ, R., 1973).

La gloria y majestad del rey hudita de Murcia, antes casi omnipotente en Al-Andalus, estaba ya en declive, iniciándose una política de pronunciamientos y autoproclamación de independencia a un ritmo tan creciente que vio discutida su autoridad, impotente para impedir la ocupación castellana de la ciudad de CORDOBA (1236), el desplazamiento del Reino de NIEBLA, del Infante D. Alfonso (1235) y frenar el avance aragonés de JAIME I hacia el sur, camino de la conquista de Valencia (1237).

Se le tornaba todo tan adverso al rey de Murcia, que se trasladó a ALMERIA, no se sabe si para acudir por mar en auxilio de ZAYYAN a Valencia o bien para abandonar el pais, camino del Norte de Africa (MOLINA LOPEZ, 1980, 223), muriendo alli asesinado por el gobernador de la ciudad Al-Ramīmī (13 enero 1238). El movimiento independentista surgido anteriormente se tradujo ahora en franca floración de nuevos Reinos Taifas, aprovechando la inexistencia de ningún poder unitario en Al-Andalus. Asi vemos reaparecer los Reinos de ALMERIA, JAEN, GRANADA, SEVILLA, MALAGA, NIEBLA y DENIA, al lado de los ya existentes de VALENCIA y MURCIA (ARJONA CASTRO, 1980).

Pero el penúltimo estaba abocado ya a su desaparición, bajo la presión persistente de JAIME I, quien obligó a su rey ZAYYAN B. MARDANIS, tras cinco duros meses de asedio, a capitular el 28 de septiembre de aquel 
mismo año 1238 (UBIETO, 1976 y 1979; GUICHARD, II, 1980; MOLINA LOPEZ, III, 1980), debiendo abandonar la ciudad del Turia y salir para Alcira y DENIA finalmente, plaza que gobernaría por medio año escaso, hasta acceder al trono del Reino hudita de Murcia (22 abril 1239), haciendo ejecutar a su titular, $A Z I Z B$. JATTAB.

ZAYYAN se convertía asi en el soberano musulmán más poderoso de Al-Andalus, logrando reunir bajo su cetro tan vastas tierras, como las enmarcadas entre el Almanzora y BAZA, por el sur, hasta el JUCAR por el norte, y las que se extienden desde el litoral alicantino hasta $\mathrm{CHINCH/-}$ LLA, junto ALBACETE, desde el Levante al Poniente. Solamente AL-AH$M A R$, rey de Granada, podía disputarle la soberanía. Los viejos Reinos de MURCIA, ALCIRA-JATIVA y DENIA se hallaban de nuevo gobernados por un solo hombre, el ex-rey de Valencia, ZAYYAN M. MARDANIS.

En su afán de alcanzar el poder marítimo que tuviera su predecesor en el trono de DENIA, Abū I-Djaysh MUYAHID (1011-1044), al extenderlo a Baleares, propuso en el verano del 1239 al rey aragonés, Jaime I, una entrevista en el Castillo de BAIREN, con el propósito de negociar el canje de MENORCA por la plaza fuerte de ALICANTE, a lo que no asintió el Conquistador, por vedárselo, dijo, la letra de antiguos Tratados de fronteras con Castilla, aludiendo implícitamente; es claro, al firmado en $C A$ ZOLA (1179), que fijaba a la Corona de Aragón la frontera de su expansión territorial por el sur en la línea BIAR-JIJONA-RELLEU-CALPE (ESTAL, 1982 y 1984).

Pero su intrusismo violento en el trono de Murcia y la proyección política de su reinado de acercamiento a los hafsies de Túnez, cuyo sultán $A B U$ ZAKARIYYA lo nombró su lugarteniente o Emir del SHARQ AL-AN$D A L U S$, de espaldas al Califato abbásida de Bagdad, le enajenó progresivamente la sumisión y obediencia de numerosas ciudades: ORIHUELA, DENIA, ALICANTE, JATIVA, LORCA, CARTAGENA, MOLINA, etc., reapareciendo una vez más el atávico espíritu de autonomía e independencia política y ANARQUIA creciente. Ejemplo altamente elocuente de tal malestar fue la creación de la denominada WIZARA ISAMIYYA o Consejo de Ministros o Ministerio de 'Isam en Orihuela, que rechazó el gobierno de Zayyan, propugnó la dependencia espiritual de Bagdad y un renacimiento literario de corte tan liberal, que convirtió aquella ciudad en un cenáculo cultural renombrado en toda Al-Andalus, al que se acogian ilustres hombres de letras, al abrigo de su proverbial hospitalidad (MOLINA LOPEZ, 1979).

Ante la creciente hostilidad de sus súbditos y proliferación de ARRAECES urbanos en rebeldia contra su gobierno, y la presión acelerada de AL-AHMAR por el $\mathrm{W}$ y el avance arrollador de JAIME I por el $\mathrm{N}$, resolvió acercarse a Castilla y solicitar el apoyo y PROTECTORADO de Fernando III, a cambio del vasallaje del Reino de Murcia (1239/40), pero sin éxito. Se ignoran las razones del fracaso (MOLINA LOPEZ, 1981, 1982). Tenía ya perdida la causa. 
La colocación de las plazas fuertes más importantes del Reino de Murcia, incluida la del Castillo de VELEZ RUBIO, en el distrito granadino de Baza, bajo la obediencia y jurisdicción del Sultán de Túnez, Abu Zakariyya, junto a los abortados intentos de AUTOINFEUDACION del mismo a la Corona de Castilla, acabó por retirarle el prestigio y toda autoridad de los súbditos, terminando depuesto por un descendiente de la derrocada dinastía Hudita y tío del célebre y poderoso IBN HUD AL-MUTAWAKKIL, de nombre Muhammad $b$. Hud Bahā al-Daw/a, el renombrado ABENHUDIEL de las Crónicas castellanas, el 11 de julio de 1241 (MOLINA LOPEZ, 1981).

Se reinstauraba asi la dinastia Hudita en el Reino de Murcia e inauguraba el gobierno del último monarca, que lo gobernaria con autonomía plena por espacio de apenas dos años, ya que, amenazado por el SW por Al-Ahmar, rey de Granada y al N por el rey de Aragón, Jaime I, optaría por acogerse pacíficamente al Protectorado de Castilla, reproduciendo el conato infructuoso de su predecesor Zayyan, con la firma del célebre PACTO DE ALCARAZ (primavera 1243). Murcia pasaba así a convertirse formalmente en un Reino-feudatario de Castilla (PRETEL MARIN, 1974; TORRES FONTES, 1973, 1980; ESTAL, 1982, 1984 у 1985).

Con ello alcanzaba Castilla el sueño dorado de su salida al Mediterráneo y ahora si de forma definitiva, excepción hecha del breve espacio de tiempo, los ocho años de hegemonia aragonesa de Jaime I/ (1296-1304). Se inauguraba asi un nuevo período del SHARQ AL-ANDALUS bajo soberanía en su parte meridional castellana, hasta que por la letra de un nuevo Tratado de fronteras, se delimitase una vez más la zona de influencia y soberanía castellano-aragonesa dentro del antiguo Reino Hudita de Murcia (Pacto de Almizra, 26 marzo 1244). El viejo reino taifa de DENIA, incorporado al Reino Hudita de Murcia desde 1229, había pasado igualmente de jure al Protectorado castellano, en virtud del Pacto de Alcaraz, si bien su ra'is, lo mismo que otros muchos de las más notables ciudades de dicho reino, no estuvieran de acuerdo con la infeudación o vasallaje del mismo a Castilla. Pero todos estos extremos son más bien tema de la II Parte de esta Comunicación, en la que nos propusimos estudiar las vicisitudes por que pasó el antiguo REINO DE DENIA bajo la hegemonia castellana, que abarca el tan breve espacio de tiempo, como el que discurre entre la firma del Pacto de Alcaraz (abril 1243) y la celebración del Tratado de Almizra (26 marzo 1244), de apenas un año, o uno y medio cuando mucho, si nos atenemos a la fecha en que el almirante del monarca aragonés, CARROZ, conquistó DENIA el 1244, incorporándola a su corona.

\section{DENIA BAJO EL PROTECTORADO DE CASTILLA (1243-1244)}

A raíz del Pacto de Alcaraz (1243) es claro que de jure el Reino Hudita de Murcia pasaba en su integridad a la soberanía de Castilla. Y queremos 
recordar que los límites del mismo iban desde el castillo de VELEZ RUBIO y el río Almanzora, al Sur, hasta el Júcar, Alcira, Játiva y DENIA al N, y desde el litoral murciano-alicantino, al E, hasta el Reino de Granada, y Yeste, Peñas de San Pedro, CHINCHILLA y ALBACETE al poniente. Tierras pertenecientes hoy, como se ve, por el litoral a Almería, MURCIA, ALICANTE, Valencia, y por el interior: Granada, Jaén, ALBACETE y Cuenca (MOLINA LOPEZ, 1980). Hemos de añadir, sin embargo, que muchas de las ciudades más importantes se habian rebelado contra la administración central hudita, y antes contra la de Zayyan, declarándose señorios independientes, nombrando sus propios ARRAECES, de espaldas al gobierno central. Sobresalieron entre otros núcleos urbanos: ALCIRA, JATIVA, DENIA, ALICANTE, ORIHUELA, MULA, CARTAGENA, MOLINA y LORCA, por citar los más significativos. Todos ellos no aceptaron el Acuerdo vasallático de Alcaraz y se opusieron en consecuencia a la soberanía castellana. Lo que explica abiertamente la actitud rebelde con que se enfrentaron los citados señoríos o ciudades al vasallaje de Castilla y la lucha obligada, con que hubo de proceder el infante DON ALFONSO para someterlas una a una por la fuerza de las armas (ESTAL, 1982 y 1984). $Y$ escribe asi un historiador de aquella efemérides: «En efecto, la toma de posesión dei reino de Murcia no fue lo pacífica que se esperaba. Alfonso se apoderó de los principales (?) castillos y fortalezas, pero no todos los arraeces del anárquico territorio musulmán de Murcia prometieron obedecerle. Tales fueron los casos de LORCA, CARTAGENA y MULA; e incluso algunos firmantes de Alcaraz no cumplieron el compromiso contraído, a veces por culpa del propio ra'is, en otras ocasiones porque la población no quiso seguir sus órdenes y ofrecieron resistencia a la ocupación castellana, como fue el caso de las ciudades de ALICANTE, ORIHUELA, ALEDO y RICOTE, motivos por los que se hubo de recurrir a las armas para asegurar el nuevo territorio castellano" (MOLINA LOPEZ, 1980 y 1984).

Por cuanto de hecho la ocupación del Reino de Murcia no fue una realidad efectiva hasta siete u ocho años más tarde, entre 1248/50. Así, Mula no capituló hasta la primavera del 1244, un año después del Pacto; Lorca, a finales de junio del mismo año, y Cartagena en la primavera siguiente del 1245 (TORRES FONTES, 1973; MOLINA LOPEZ, 1980).

Las ciudades de ALICANTE y ORIHUELA opusieron igualmente resistencia armada al vasallaje castellano. Sabemos que el ex-rey de Valencia y MURCIA, ZAYYAN B. Mardanis, fue desterrado por IBN HUD a Alicante, en condición de ra'is de la misma, donde permaneció hasta 1247/48, fecha en que parece que partió para Túnez, al lado del Sultán hafsí, su antiguo aliado (MOLINA LOPEZ, 1981; ESTAL, 1982). Lo que se ajusta mejor a los hechos más conocidos, como la fecha de la concesión por Alfonso $X$ el Sabio de su FUERO a ALICANTE (agosto 1252), la creación de su CONCEJO y la dotación de un sinnúmero de franquezas, a base del Fuero de Cordoba y las franquiciaș otorgadas a Cartagena (ESTAL, 1982, y «Estu- 
dio y contexto hist. del Cartulario de Alfonso X el Sabio a Alicante", edic. facsímil EDILAN Madrid, 1984; Documentos inéditos de Alfonso $X$ el Sabio, Alicante, 1984).

De Orihuela sabemos también que se mantuvo rebelde a la dominación castellana, conservando su independencia frente al poder central, fiel a la política ya tradicional de la conocida Wizara 'Isamiyya, hasta finales de la cuarta década del 1200. Escribe así un historiador de la misma: "Orihuela continuó gozando de una independencia y autonomía casi absolutas, por lo menos hasta los años 1249/50, fechas en las que todavía se tienen testimonios de actos públicos realizados por el Consejo (de su Wizara Isamiyya), siendo Abū l-Hasan, hijo de Abū Isam, el nuevo ra'is de Orihuela" (MOLINA LOPEZ, 1981). Lo que se ajusta mejor igualmente a la documentación despachada por Alfonso el Sabio a favor de esta villa, a la que no otorgó sU FUERO hasta 1265 y a tenor del conferido anteriormente a Alicante, iniciando entonces la colación de numerosas franquezas y el propio REPARTIMIENTO, ya en prensa (ESTAL, 1982), asi como la constitución de su Concejo, a partir del año citado. Talesactos de orden por entero administrativos e institucionales no tendrían fácil explicación, de aceptarse como válida, pero sin documentar, la tesis de quienes afirman gratuitamente (BALLESTEROS, 1943; GISBERT BALLESTEROS, I, 1902; FONT RIUS, 1951 y 1956) que el Reino de Murcia pasó integramente, a excepción de las pocas plazas expresamente citadas (Primera Crónica Gral., II, 744, ed. MENENDEZ PIDAL): «Mula et Lorca et Cartagena", a la soberania de Castilla en la primavera del 1243, a raiz del Pacto de Alcaraz. ALFONSO EL SABIO no se vio de verdad soberano efectivo y real del entero Reino hudita de Murcia hasta los años 1249/50, y no por la letra de un simple Acuerdo pactado, tan sólo, sino más bien y sobre todo por la fuerza imperiosa de las armas (ESTAL, 1984).

Pero existía un enclave superior en el Reino de Murcia que, aunque administrativamente pertenecia desde el 1229 al reino hudita, por conquista, geográficamente estaba más próximo a Valencia y le estaba adscrito su derecho de conquista al rey de Aragón, en virtud de lo pactado en CAZOLA (1179) por sus mayores, Alfonso VIII de Castilla y Alfonso II de Barcelona (ESTAL, 1982). Correspondía aquel enclave al Sur del Júcar, a las tierras comprendidas entre el cauce del mismo y la linea fronteriza de Biar - JIJONA - Calpe, trazada en el Pacto antes citado. Destacaban entre otras las ciudades más pobladas e importantes, las de ALCIRA, bordeada por el propio río; JATIVA y DENIA, en cuya ocupación se hallaba empeñado insistentemente JAIME I por las mismas fechas, ansioso de alcanzar de facto la frontera asignada a su Corona en el pacto referido.

ALCIRA: Fue sometida a finales del 1242 o principios del 1243 (DESCLOT, Crón. c. XIX).

JATIVA: Inició su asedio el 1243 y no capituló hasta junio de 1244 (Crón. Jaime I, c. 339 s.). 
DENIA: En 1244 por obra del amirante CARROZ, a quien premiaría ampliamente Jaime I con abundantes heredamientos dentro y fuera de la ciudad, siendo a la sazón su arráez YHAVE ABU L-HUSEIN, destacado literato y poeta (CHABAS, I, 192).

A principios de marzo del 1244 se presentó el infante don ALFONSO ante los muros de JATIVA, decidido a ocupar aquella enhiesta plaza, a la que por su parte tenía puesto sitio JAIME / desde noviembre del año anterior, por razón de las negociaciones secretas de su alcayde con el infante castellano para rendirle la plaza (Crón. de Jaime I, c. 339 y 340). Uno y otro monarca propendian con todo derecho (según el Pacto de CAZOLA, Jaime I, y según el firmado en ALCARAZ, el infante don Alfonso) a ocupar las plazas extremas que les correspondían, al límite de sus Reinos respectivos, el de VALENCIA para el monarca aragonés y el de Murcia para el castellano. Amparados en sus respectivos derechos apuntados, entrambos monarcas pretendian la ocupación de JATIVA. Ante la dificultad de un entendimiento mutuo y resolutorio del problema fronterizo, uno y otro se arrogaron indebidamente plazas del contrario. ENGUERA y MOGENTE, de innegable pertenencia a Aragón, fueron ocupadas por huestes castellanas (Crón. de Jaime I, c. 342) y en revancha recíproca Jaime l le arrebató al castellano las de VILLENA, SAX, CAUDETE y BUGARRA, de asignación asimismo inequívoca por los Pactos consabidos a Castilla (ib., c. 343). La guerra civil entre ambos monarcas parecía inevitable ya, de no haber intervenido a tiempo la reina de Aragón, D. ${ }^{a}$ VIOLANTE o YOLANDA, convenciendo a entrambos de la necesidad imperiosa de una entrevista dialogante para llegar a un mutuo Acuerdo de fronteras. El resultad o feliz fue el TRATADO DE ALMIZRA, firmado el 26 de marzo de aquel mismo año (Crón. cc. 343-349; ESTAL, 1982), que fijaba una FRONTERA casteliano-aragonesa fluvial (CABRIEL y AYORA desde su confluencia en el JUCAR), orográfico-(PUERTO DE BIẢR) toponimica (BIAR, CASTALLA, JIJONA, BUSOT y AGUAS, más VILLENA, ALMIZRA y BUGARPA, para acabar en el BARRANCO DEL CARRICHAL al Sur de Villajoyosa, en su actual límite municipal con CAMPELLO) (ESTAL, 1983; 1984, Congr. H. ${ }^{\text {a }}$ Albacete, II Edad Media, pp. 48-79; 1984, Documentos inéditos de Alfonso el Sabio, passim). Quedaba resuelto al fin el espinoso problema fronterizo, pudiendo encaminarse uno y otro príncipe a ultimar la ocupación de las restantes plazas insumisas de sus respectivos Reinos. Castilla no dominaba aún por entero el Reino hudita de Murcia, quedándole numerosas JIJONA-VILLAJOYOSA.

JATIVA: Capituló al fin en junio de 1244.

DENIA: Conquistada por el almirante CARROZ en julio del mismo año, 1244

BIAR: Lo alcanzaba Jaime I en febrero del 1245.

Traduciendo en realidad aquel mismo año la expansión territorial asig- 
nada a su Corona en el recién concluido TRATADO DE ALMIZRA ya expuesto.

Como se desprende de cuanto queda dicho, DENIA quedaba enmarcada en la Corona de Aragón, dentro del REINO DE VALENCIA, iniciándose a partir de aquí, julio del 1244, el tercer capítulo de nuestra Comunicación, concerniente a su historia bajo la soberanía ahora de Aragón, dentro de la demarcación administrativa de la PROCURACION UItra XUcarum, entre el Júcar y Jijona-Villajoyosa.

\section{DENIA BAJO LA SOBERANIA DE ARAGON Y REINO DE VALENCIA} (1244-1304)

La expansión territorial de la Corona de Aragón por el litoral mediterráneo hacia el Sur peninsular por debajo del JUCAR, obligó a la corona a remodelar la DIVISION ADMINISTRATIVA del REINO DE VALENCIA, al duplicarse casi su territorio, con la ocupación de las nuevas tierras hasta JIJONA-VILLAJOYOSA, primero, y luego (1296-1304) hasta bajo Segura (ESTAL, 1985).

Se tomó al Júcar como término de la primitiva PROCURACION DE VALENCIA, creándose ahora, a partir del 1245, una segunda Procuración valenciana, con la denominación de PROCURACION ultra Xucarum, más allá del citado río hacia el Sur (LALINDE ABADIA, 1963).

$Y$ así se mantuvo esta denominación hasta que JAIME |l amplió el REINO de Valencia más hacia el Sur, incorporando al mismo la región septentrional del REINO DE MURCIA, tras ceder la más meridional del mismo a Castilla (Sent ${ }^{2}$ Arbitral TORRELLAS, 1304) y crear entonces la PROCURACION GRAL. DE ORIHUELA O REINO DE VALENCIA ultra Sexonam, que abarcaba las tierras comprendidas entre BIAR - JIJONA VILLAJOYOSA hacia el Sur, hasta el limite municipal de ORIHUELA con MURCIA, coincidente hoy con el límite interprovincial de ALICANTE y MURCIA (ESTAL, 1982 y 1985).

A partir de esta fecha (1304) se divide el Reino de Valencia en dos nuevas jurisdicciones administrativas: REINO DE VALENCIA, 'sin más apelativos, abarcando todas sus tierras desde el Cenia, límite fluvial más al norte del mismo, entre Castellón y Tarragona, hasta JIJONA y no ya el Júcar, como anteriormente, y REINO DE VALENCIA ULTRA SEXONAM, más arriba descrito. Al frente de cada uno de ellos se hallaba un PROCURADOR GRAL. que lo gobernaba en nombre del rey, con poderes delegados del monarca. En la esfera politica. En la económico-administrativa el funcionario supremo era el BAYLE GENERAL, con poderes delegados asimismo del monarca.

PEDRO IV de Aragón cambió esta denominación (1363/1366) por la de GOBERNACION GENERAL de Valencia y de ORIHUELA, que perduró 
hasta la abolición de los Fueros del Reino por el Decreto de Nueva Planta del 1707 de Felipe V.

La historia de DENIA de esta época (1244-1304) hay que enmarcarla, pues, dentro de la división administrativa referida del REINO DE VALENCIA ultra Xucarum.

Es lógico pensar que la NORMA INSTITUCIONAL SUPREMA otorgada por JAIME I a las gentes de los núcleos urbanos de esta demarcación apuntada, entre los que hay que destacar los de ALCIRA, JATIVA y DENIA, está plasmada en los FURS que hizo compilar para la ciudad y Reino de Valencia, a raíz mismo de su conquista.

El estudio y análisis de los PRIVILEGIOS REALES concedidos sucesivamente a la misma por los monarcas de Aragón: JAIME I, PEDRO III, ALFONSO III y JAIME II, entre 1244 al 1304, seria el paso especifico a dar, para llevar a cabo una investigación primigenia y original al respecto, sobre la que pueda cimentarse con solidez histórica el pasado medieval de estos lugares y muy particularmente de esta ciudad de DENIA. Pero tales fondos manuscritos aquí no existen y hay que buscarlos en otros Archivos, como el de ALCIRA y sobre todo el de la Corona de Aragón (ACA), cuya triple serie de fondos de valor incomparable: PERGAMINOS $=21.196$; CARTAS REALES DIPLOMATICAS O LEGAJOS $=50.000, \mathrm{y}$ los REGISTROS reales $=8.619$, que arrojan en conjunto un volumen de más de 4.000.000 de documentos, es donde se nos ofrece un material insospechado, todavia sin explotar, con que construir nuestra verdadera HISTORIA. Valga como ENSAYO aplicable a DENIA elFUERO que otorgó Jaime II al REINO DE MURCIA a raiz de su conquista, con fecha 25 oct. de 1297.

Por ser el Reino de Murcia uno de los territorios incorporados últimamente a la Corona de Aragón, dentro de la Península, y dotado por JAIME II de IOS FUEROS precisos para su adecuado gobierno y administración, entre los años 1296 y 1304 , periodo en que formó parte integrante de la referida Corona, voy a servirme de análisis comparativo, aplicable a $D E$ NIA por tratarse aquí de una ciudad incorporada también posteriormente al Reino de Valencia.

Por carta del 3 julio 1296 ordenaba Jaime ll al Justicia de Murcia, D. PEDRO JIMENEZ DE SPILONGA, que, en tanto que se compilan los nuevos FUEROS de Murcia, se sirvan mientras de los que le otorgara ALFONSO EL SABIO: “utamini FORO quo utebamini tempore illustris domini ALFONSI quondam Regis Castellae» (ESTAL 'Confirmación de Fueros a... Murcia', 1982, $n^{\circ}$ XVIII).

$Y$ con idéntica fecha encomendaba la singular tarea de compilar el FUERO DE MURCIA a dos ilustres legistas castellanos, residentes en aquella capital: MARTIN DE DIOS y JUAN MAEYANI (ESTAL, ib., Misc. . Mval. Murc., IX, 1982, $\mathrm{n}^{\circ} \mathrm{XIX}$, p. 280). A los que sumaba un tercer miembro cualificado en la persona del jurisconsulto leridano y canónigo: RAMON 
CABRERA (ACA, REG. 253, fol. 3 r.; ESTAL, 1982, ib.), quienes habian de servirse para su compilación de los FURS DE VALENCIA, 'muy buenos', y de las COSTUMS o consutudines regionales del lugar, las que habrian de respetarse en todo momento con máximo rigor.

Un año después sancionaba JAIME II el FUERO DE MURCIA, compilado en un volumen de cuatro libros, imponiendo su fiel cumplimiento y aplicación a partir de la fecha, el 27 oct. 1297, conminando severas penas a sus infractores y ordenando que se hagan copias abundantes de los mismos, con destino a todas las villas y demás lugares del REINO DE MURCIA, (ESTAL, Fueros al Reino de Murcia, (1984 pp. 123-125; 1985).

A partir, pues, de esta fecha (25 oct. 1297) tenía ya el REINO DE MURCIA sU FUERO propio, que pasaba a sustituir el viejo Fuero castellano precedente de Alfonso el Sabio.

Pese a la importancia trascendental de este FUERO NUEVO murciano, aragonés, ha desaparecido, sin que se conozca la pista del mismo. Esperemos que un buen día reaparezca, debido a las numerosas copias que se ordenaron hacer del mismo. Faxit deus!

Sin embargo, poseemos afortunadamente un volumen tan considerable de PRIVILEGIOS REALES de aquel monarca a la ciudad y Reino entero de Murcia (ESTAL, Corpus Dtal. del Reino de Murcia bajo Aragón, 1296-1304 (1985), con más de 250 documentos inéditos) que podemos todavia rastrear con garantía absoluta aquel FONDO INSTITUCIO$N A L$, que debía contener el perdido FUERO DE MURCIA y de todo su REINO.

\section{ANEXO DOCUMENTAL}

\section{6, AGOSTO 29. MURCIA.}

Traslado notarial de una Carta de Jaime II de Aragón al Consell de la ciudad de Murcia, en respuesta a una serie de Capítulos o cuestiones formuladas por el mismo, catorce en total, concernientes a los fueros y libertades de que venía disfrutando de tiempo atrás y muy particularmente bajo la hegemonia castellana (1243-1296), solicitando la confirmación de cada fuero en términos precisos y sus aclaraciones pertinentes. El presente Traslado fue confeccionado por Domingo Soler, notario público de Murcia, a la vista de la Carta original del monarca aragonés, lo que atestigua así: "aquest treslat escriure fiu e comproue con el padron" en el escatócolo, el 29 de agosto de 1334 de la Era Hispánica, el 1296 de la cristiana, sin que nos certifique la fecha del original, la que necesaria- 
mente fue posterior al 19 de mayo de aquel año, día en que conquistó Jaime Il aquella capital. La confirmación real es escueta, con un simple "plau al Sennyor Rey", salvo cuando excepcionalmente añade alguna aclaración, precisión mayor, rectificación o reserva a la cuestión formulada.

ACA, Cartas Reales Dipl., Jaime II, Caj. 2, N. ${ }^{\circ} 289$.

Publ. ESTAL, 1985, $n^{\circ} 141$, pp. 256-260

Aquest aço es treslat de una Carta en que son escrits los Capitols de les graçies e de les merçess, que el molt noble Seynor don Jayme por la graçia de deu Rey/Darago, de Mayorcas, de Valencia etc. al Consell de Murçia segons que a fet scriure, la qual es sagellada ab lo son segell, etc/. Aquestes son les graçies e merçess que el Cosell de Murçia demana al Senyor Rey/ (dividimos con numeración arábiga los 14 Capitulos y separamos en su transcripción, a efectos de mayor claridad).

1. Primerament que en nengun temps sels partira de la sua Corona ni del seu Sennoryiu per nenguna raho/.

E plau al Sennyor Rey e atorgaho/.

2. Item quels conferm los furs e Priuilegis e Franquesses e Libertats e Merçess e Honrres e bons uses que an del Rey Don ALFFONSO, que parays aia, e dels altres que pus del regnaren en Castella/. (Confirmación de los privilegios otorgados por el Rey Sabio, Sancho IV y Fernando IV de Castilla, desde 1243 hasta la fecha.)

E plau al Sennyor Rey/.

3. Item quels confferm la petiçio que fo feyt de Murçia e les donaçions en general e en espeçial, axi en cascunes casos de corporal possessio/.

E plau al Sennyor Rey, salu dret dun Rey al altre/. (Confirmó Jaime II a Murcia y a sus vecinos todas las donaciones efectuadas, salvo aqueIlas que pudieran lesionar los derechos reales.)

4. Item que quant tota questio o demanda que Consell pogues fer contra alguns de qualque raho o malefiçi, que aguessen fet en la sua terra o en terra de Murcia e/ de tota altra iusticia e pesquises e iustificaçions de qualque raho sien tro al dia duy/. E lo Sennyor Rey o perdona en quant en Consell es tot ço que feyt sia entro/ el dia de huy, sia fet en pau o en guerra o en treua, mas si a algun hom desta terra aujen repres en pau o en treua, quels en façen dret/.

5. Item a tots les persons que son feyts axi duneys contra daltres coses ab Cartes dels Reys o dels Adelantats que sien franchs (? borrado)/. E plau al Sennyor Rey/.

6. Item que tots les veys de Murçia sien franchs generalment per tot lo seu Sennyorjo per Mar e per terra, axi en ço que huy a, com daquauant aura/.

E plau al Sennyor Rey/. 
7. Item quels Jueus, e els Moros sien salues persones en tot lo seu/. E Plau al Sennyor Rey/.

8. Item que tots aquelles que aquesta auinença se uolrran esser, que putxen (?) anar salus quascuns ab tot lur moble, e si dins $X X X$ dies uolrran tornar a la merçe del Rey, que no perden/ res de lur. E si lur res (borrado: fo?) ab ells pres, remanga salu ab lur dret e que (borrado: non minus?) sien entesses Jueus e Christians/ e si qualguns son fora de la terra (borrado: al temps que?) dara e dins $X X X$ dies pusque auran jurat al Sennyor Rey, uolrran uenir a merçe del Rey que (borrado: ne?) prenda (?) lo seu/.

E plau al Sennyor Rey del dret que buy (sic) y han/.

9. Item que tots los vehins de Murçia que alguna cosa agen en qualque lugar del Regne, quels sian salus/.

E plau al Sennyor Rey/.

10. Item que tots los pleits qui son determenats e passats en cosa juitgada, quant per Juy o per Cartes dels Reys, que no pusquen esser altra uegada retrotrats/.

E plau al Sennyor Rey/.

11. Item que tots les cartes publiques et les altres escriptures dels plets (sic), ques façen en uulgar (se confeccionen y redacten en romance) per la part que les gens plus clarament o entenen/.

E plau al Sennyor Rey/.

12. Item que (borrado: siempre que?) totes quantes donacions el Consell auia fetes o atorgades a alguns de cases o de heredaments o de rendes o de qualques altres coses a los/ uehins de Murçia e quels o conferm axí com cascunes an possessio del Rey o en altra manera/. $E$ atorgao lo Sennyor Rey leuar aquells que dintre los XXX dies nol auran regonegut per Sennyor/ (confirmación general a todos de los bienes recibidos por donación real o de otra persona, a excepción de aquéllos que se nieguen o resistan a acatarlo por soberano).

13. Sennyor, per que entenem que es uostre seruj e de la terra, clamam uos merçe, que pusgam traure del Regne pan e uin e tots altres uiandes, franquesses e quantes coses/a portar en tots parts, salu en terra dels uostres enemics/. (Disfrute de franquicia de leuda y portazgo por todas las tierras del Reino de cuantos productos de pan y vino y otras mercaderías precisen transportar.)

E plau al Sennyor Rey. Exceptat com lo Sennyor Rey fees uet general per tot/. (Afirmativamente a todo, salvo a las «coses vedades» ya conocidas.)

14. E atrossi, Sennyor, quens façats merçe en lexar nos pẹndre les rendes del Regne de Murçia tro que aiam pagats X Mill Solidos, quel Consell a man leuar per adobar/los Murs e les Torres de la Vila e que prestaren a JOHAN SANCHEZ e als castellans sobre estes rendes, les 
quales els tenjen e prenjen per manament/ e Cartes del Rey (Alfonso $X$ y sucesores) e quens hi façats aquella ajuda que tingats per be/. (Que les faculte retener los ingresos municipales hasta que puedan amortizar la suma de 10.000 sueldos que por orden real hubieron de entregar a Juan Sánchez, Adelantado del monarca de Castilla para restaurar las murallas y torres defensivas de Murcia.)

E daquest Capitol parlara en Bernat de Sarria ab ell/. (Jaime II remitió la solución del asunto en cuestión a la entrevista que en breve iba a celebrar con el bayle general del Reino de Murcia. Bernat de Sarriá, para informarse previamente al detalle del estado de las cuentas y prestaciones pecuniarias aludidas.)

Sennyal (signo notarial) de mi Domingo de Soler, notarj public de Murçia, que aquest treslat escriure fiu e comproue con el padron (el original de Jaime II), XXIX dies Augusti/ era de mill e CCC e XXX quatre ans/ (1).

(1) Día 29 de agosto de 1296. Es una Carta real de singular interés para la historia de la conquista aragonesa de la ciudad de Murcia, por numerosas razones. Se nos confirma en ella la existencia de unos fueros y libertades, que se remontaban a la hegemonía castellana, pidiendo de todos su ratificación actual. Lo mismo ha de decirse del salvoconducto y guiaje de que gozaban hasta la fecha los vecinos de Murcia, para poder moverse con entera seguridad y libertad por las tierras del Reino, y de los que se ruega la confirmación real. De singular relieve es el respeto que se exige para todas las personas y bienes de moros y judios, igual que de los cristianos, sin discriminación de ningún tipo, claro exponente de la voluntad del monarca de tratar a todos por un igual, con idénticos derechos y obligaciones. Es sintomática también la disposición real de redactar las Actas judiciales y demás escrituras públicas en romance, al objeto de hacerlas más inteligibles a toda la población. Y la presente copia o traslado de la Carta real es ya un ejemplo elocuente, al ofrecerla en valenciano, en un Concejo que hasta pocos dias antes habia estado bajo el gobierno de Castilla y todas sus disposiciones se habian redactado en castellano, y el catalán les tenia que resultar una lengua extraña y desconocida. Pues los catalanes asentados por Jaime I en Murcia en 1266, por numerosos que fueran en un principio, treinta años después, de seguro que estaban en minoria frente a la población castellana, llegada alli en las sucesivas repoblaciones llevadas a cabo por los monarcas Alfonso $X$, su hijo Sancho IV y el propio Fernando IV, el Emplazado.

Finalmente, hay que subrayar la disposición benevolente de Jaime II a complacer en sus demandas a los vecinos de la ciudad de Murcia, en primer lugar por estimarlas justas y obligadas para una población heterogénea confesionalmente, pero que al ser todos súbditos suyos por un igual, no quiso discriminarlos en modo alguno, seguro de ser éste el mejor camino para captarse desde el principio la simpatía y leal servicio de todos, consciente de que la población mayoritaria seguian todavia integrándola en el Reino de Murcia los miembros de las Aljamas tanto moras como judias, que pululaban con superioridad ciertamente desbordante sobre los núcleos cristianos, asentados allí con posterioridad a la ocupación reciente del año 1243 en adelante, por obra sucesiva de Castilla y a veces simultánea de Aragón, en 1266, al menos, bajo la égida de Jaime el Conquistador.

Vid. ESTAL, J. M. del, "Confirmación de fueros a la ciudad y Reino de Murcia por Jaime II de Aragón, 1296-1304", en Miscelánea Medieval Murciana, IX, 1982, pp. 244-247. Versión casteIlana de la carta, original del autor, ibid., pp. 248-255, acompañada del correspondiente comentario documental histórico.

ID., Conquista y anexión de las tierras de Alicante, Elche, Orihuela y Guardamar al Reino de Valencia por Jaime /l de Aragón (1296-1308), Alicante, 1982, pp. 359-363.

ID., El Reino de Murcia bajo Aragón (1296-1304/5), pp. 256-260 y passim. 
1. JURAMENTO Y COMPROMISO FORMAL regios de no separar jamás de la Corona ninguno de los lugares, villas y ciudades del Reino (ACA, Reg. 340 , fol. 288 r).

2. OBLIGACION ineludible de todo ciudadano de acatarlo como a su soberano y señor, en el plazo de 30 días, transcurridos los cuales no se admitirá excusa alguna y se procederá contra los rebeldes, confiscando sus bienes (ACA, Reg. 340, fol. 182-183r).

3. Privilegios de favor especial, DONADIOS y HEREDAMIENTOS a sus fieles servidores, a base de los bienes confiscados a los rebeldes (ib., fol. 283).

4. Concesión de amplias FRANQUEZAS y LIBERTADES a todos los moradores del REINO DE MURCIA, sin excepción de ETNIA o RELIGION, tanto a los MUDEJARES como a los JUDIOS, haciendo a todos objeto de la exención de lezda y peaje por todos sus reinos, dejando a salvo les COSESS VEDADES ya conocidas: armas, hierro, caballos, etc. (ACA, Reg. 340, fols. 76 r, 107-108 v, 119 r, 122 r, 280 r, 283 v-284 r).

5. INDULTO GRAL. de toda infracción perpetrada con anterioridad a la conquista, tanto en guerra, tregua o paz, siempre que se le acate como a soberano y señor (ib., f. 143).

6. Orden de redactar las ACTAS JUDICIALES en romance y lengua vulgar: "quod omnia INSTRUMENTA et SCRIPTURE PUBLICE conficiantur et fiant vulgariter» (ib., f. $283 \mathrm{v}$ ).

7. Confirmación de los COSTUMS y USOS TRADICIONALES del Reino de Murcia, vedando a todo alto funcionario gravar a los súbditos con cargas fiscales en contra de sus COSTUMS y FUEROS: “juxta predictas eorum consuetudines seu Privilegia per Nos confirmata ac per eOS ACTENUS USITATA, non gravetis seu gravari ab aliquo permittatis» (Játiva, 8 agosto 1296, ACA, Reg. 340, fol. 285 v).

Con estas disposiciones sancionaba JAIME / IOS VIEJOS USOS TRADICIONALES y las COSTUMBRES CENTENARIAS de los vecinos del Reino de Murcia, confirmando a su vez como buenos los PRIVILEGIOS ALFONSINOS, base de sus primitivos Fueros, cuyo contenido consuetudinario mandaba ahora respetar en IOS NUEVOS FUEROS que acababa de promulgar para la ciudad y Reino de Murcia, mediante la Provisión real referida (25 oct. 1297). DENIA no pudo ser una excepción en el sontexto global del REINO DE VALENCIA ultra XUCARUM, y queremos presumir que recibió al lado de los FURS valentinos los propios FUEROS, a base de los anteriores y de nuevos PRIVILEGIOS reales, que sin duda, como en el caso del Reino de Murcia, existen y aquí también existieron. ¡Es un reto noble a la Investigación! 
ALFONSO X EL SABIO, Primera Crónica General, ed. MENENDEZ PIDAL, R., II, Madrid, 1906, 3. ${ }^{2}$ ed., M-1877.

ARJONA CASTRO, A., Andalucia musulmana. Estructuras político-administrativas, Córdoba, 1980.

BALLESTEROS BERETTA, A., "La reconquista de Murcia, 1243-1943", en BRAH, CXI, Cuad. I y II, 1943, pp. 133-150.

- "La reconquista de Murcia por el inf. don Alfonso de Castilla", en Murgetana, I, 1949, pp. 9-48.

BURNS, R. I., The Crusader Kingdom of Valencia, 2 vols., Cambridge, 1967.

BARCELO TORRES, M. ${ }^{*}$ C., "Inventario de documentos árabes alicantinos", en Ridea, 37, 1982, pp. 53-65.

ARIÉ, R., España Musulmana, ss. VIII-XV, Historia de España dirigida por Tuñón de Lara, Ed. Labor, III, Madrid, 1982.

CHABAS, R., Historia de la ciudad de Denia, Denia, $1874,2 .^{a}$ ed. facsímil, Alicante, 1972.

- «El Capitán Carroz", en El Archivo, II, 1887, pp. 30-36 y 77-84.

EPALZA, M., "Importancia de la historia árabe en Denia», en Dianium, I, Denia, 1983, pp. 46-49.

ESTAL, J. M. del, "Conquista y anexión de Alicante al Reino de Valencia», en Ridea, 15, 1975, pp. 127-158.

- "Fuero de adscripción de las villas de Orihuela y Alicante a la Corona de Aragón», en Misc. Mediev. Murciana, V, 1980, pp. 11-34.

- "Alicante en la política territorial de los dos Jaimes de Aragón", X CHCA: Jaime / y su época, Zaragoza, vols. 1 y 2, 1980, pp. 65-80.

- "Conquista y repoblación de Alicante y Orihuela por Alfonso X el Sabio", en Ridea, 33, 1981, pp. 65-102.

- "Carta-Magna de Jaime II de Aragón a las villas de Orihuela, Alicante, Elche y Guardamar en su anexión al Reino de Valencia, a. 1308", en Anales de la Univ. de Alicante. Historia Medieval, N. ${ }^{\circ} 1,1982$, pp. 47-78.

- "Fueros de Jaime II a la ciudad y Reino de Murcia (1296-1304)", en Misc. Mediev. Murciana, IX, 1982, pp. 241-292. Anexo documental de 29 documentos.

- «Alicante Medieval en la encrucijada de dos culturas y pueblos: Musulmanes y Cristianos", en Alborada, Elda, 1983, pp. 47-51.

- «Término disputado por Alicante y Villajoyosa en la frontera de Almizra», en Rev. de Moros y Cristianos, Villajoyosa, 1983, p. 66.

- "Traslado notarial inédito de ciertos Fueros otorgados a la ciudad y Reino de Valencia. 1251-1302», en Ridea, 40, 1983, pp. 25-68.

- Documentos inéditos de Alfonso $X$ el Sabio y su hijo el Infante D. Sancho, Alicante, 1984. Estudio, transcripción y comentario histórico.

- "Las tierras levantinas de Albacete...dos tercios últimos s. XIII", Congr. H. albacete, II 1984, pp. 49-79.

- «Fueros y sociedad en el Reino de Murcia bajo la hegemonia de Aragón, 12961304 ", Anales H. ${ }^{a}$ Mval., Universidad Alicante, n. ${ }^{\circ} 3,1984$, pp. 99-130.

- Conquista y anexión de las tierras de Alicante, Elche, Orihuela y Guardamar al Reino de Valencia por Jaime II de Aragón (1296-1308), Alicante, 1982.

- Corpus documental del Reino de Murcia bajo la soberania de Aragón, 12961304. Estudio, transcripción y comentario de 254 documentos, en su mayor parte inéditos, Alicante, 1985.

ESTAL, J. M. del, y otros, El Libro de los primitivos privilegios de Alic. de Alfonso $X$ el Sabio, ed. facsímil, M. 1984. 
GISBERT Y BALLESTEROS, E., Historia de Orihuela, 3 vols., Orihuela, 1901-1903.

GONZALEZ, J., Repartimiento de Sevilla, 2 vols., Madrid, 1951.

- Reinado y diplomas de Fernando III, I, Córdoba, 1980, II, 1983.

GONZALEZ JIMENEZ, M., La repoblación de la zona de Sevilla durante el siglo XIV. Estudio y documentación, Sevilla, 1975.

GUICHARD, P., Nuestra Historia, III, Valencia, 1980.

HUICI MIRANDA, A., Historia musulmana de Valencia y su región, 3 vols., Valencia, 1969-1970.

LALINDE ABADIA, J., La Gobernación General en la Corona de Aragón, Madrid, 1963.

- La Corona de Aragón en el Mediterráneo Medieval (1229-1479), Zaragoza, -1979 .

FURS DE VALENCIA, ed. Germa Colón y Arcadi García, 3 vols., hasta ahora, E/s Nostres Classics A:101, Barcelona, 1970.

FURS e Ordinacions fetes per los gloriosos reys de Aragò als regnicols del Regne de Valencia, Valencia, 1482, ed. facsímil, 1977.

LLORENS I RAGA, Pelegrí L., "Presencia hist. de la sede de Segorbe en el Reino de Valencia", en Bibl. de estudios de Segorbe, 15, Segorbe, 1960.

- "Segorbe-Castellón, Diócesis de", en Dic. H. Ecl. de España, IV, Madrid, 1975, pp. 2389-2393.

- Episcopologio de la diócesis de Segorbe, 3 vols., CSIC, 1973-1974.

MOLINA LOPEZ, E., Murcia y e/ Levante español en el siglo XIII (1224-1266) a través de la correspondencia oficial, personal y diplomática, Granada, 1978.

- «Aziz b. Jattab, destacada personalidad política, científica y literaria murciana del siglo XIII», en Misc. Mval. Murc., IV, 1978, pp. 65-86.

- «El Levante y Almería en el marco de la política interior de Ibn Hud al-Mutawakkil (1236-1238)", en AWRAQ, II, 1979, pp. 55-63.

- «La = Wizara 'Isamiyya $=$ de Orihuela», en Anales del Col. Univ. de Almeria, i, 1979 , p. 78.

- «Murcia en el marco histórico del segundo tercio del siglo XIII", en Historia de la Región Murciana, III, Murcia, 1980, pp. 187-263.

- «El gob. de Zayyan b. Mardanis en Murcia, 1239-1241», en Misc. Mval. Murc., VII, 1981, pp. 159-190.

- $« E I=$ Sharq al-Andalus = en el siglo XIII. Aspectos políticos y sociales», en Ridea, 37, 1982, pp. 7-31.

OLIVER SANZ DE BREMOND, E., Historia de Denia, Valencia, 1978.

PRETEL MARIN, A., Alcaraz, un enlace en la trontera del siglo XIII. Prólogo del Dr. Juan Torres Fontes, Albacete, 1974.

RUBIERA MATA, M. J., La Taifa de Denia, Alicante, 1985.

TORRES FONTES, J., «El reino musulmán de Murcia en el siglo XIII», en Anales de la Universidad, X, 3, Murcia, 1952, pp. 259-274.

- Repartimiento de Murcia, Murcia, 1960.

- La reconquista de Murcia en 1266 por Jaime I de Aragón, Murcia, 1967.

- Incorporación del Reino de Murcia a la Corona de Castilla, Murcia, 1973.

- CODOM (Colección de Documentos para la Historia del Reino de Murcia). I, Documentos del siglo XII, Murcia, 1963; II, Siglo XIII, Murcia, 1969; III, Fueros de Alfonso el Sabio al Reino de Murcia, Murcia, 1973; IV, Privilegios de Sancho IV, Murcia, 1977; V, Documentos de Fernando IV, Murcia, 1980.

- "Murcia castellana", en Historia de la Región Murciana, III, Murcia, 1980.

SANCHIS GUARNER, M., Historia del Pais Valencia. Epoca Musulmana, Barcelona, 1965.

UBIETO ARTETA, A., Origenes del Reino de Valencia. Cuestiones cronológicas sobre su reconquista, I, 2. ${ }^{a}$ ed., Valencia, 1976; II, Valencia, 1979. 
VALLVE BERMEJO, J., «El Reino de Murcia en la época musulmana», en Rev. del Inst. Egipcio de Estudios Islámicos, XX, Madrid, 1979-80, pp. 22-64.

VILAR, J. Bta., Historia de la ciudad de Orihuela. II, Orihuela musulmana, Orihuela, 1976; III, Los siglos XIV y XV en Orihuela, Orihuela, 1977. 